\title{
Observational analysiS of out-of-hospital Cardiac Arrest occurRence and temporal variability patterns in subpopulation of southern POLand from 2006 to 2018: OSCAR-POL registry
}

\author{
Stanisław Szczerbiński ${ }^{1 *}$, Jakub Ratajczak ${ }^{2,3 *}$ (D), Małgorzata Jasiewicz ${ }^{3}$, Aldona Kubica ${ }^{2}$ (1) \\ ${ }^{1}$ Emergency Medical Center in Opole, Poland \\ ${ }^{2}$ Department of Health Promotion, Nicolaus Copernicus University, \\ Collegium Medicum in Bydgoszcz, Poland
}

${ }^{3}$ Department of Cardiology and Internal Medicine, Nicolaus Copernicus University,

Collegium Medicum in Bydgoszcz, Poland

\begin{abstract}
Background: Temporal variability of out-of-hospital cardiac arrest (OHCA) occurrence was presented in previous studies, however, the data regarding long-term observation is scarce. The aim of this study was to investigate the temporal variability of OHCA occurrence during a long-time period and analyze the circadian pattern within particular timeframes.

Methods: The retrospective analysis of $5058 \mathrm{OHCA}$ cases was made covering the period from January $1^{\text {st }}$, 2006 to December 31 ${ }^{\text {st }}$,2018. Circadian, weekly, monthly and seasonal variabilities were investigated. The circadian variability of OHCA occurrence was assessed within particular years, seasons of the year, and days of the week.

Results: The highest OHCA incidence was observed between 08:00 and 08:59 and the lowest between 01:00 and 01:59 (7.1\% vs. 1.6\%, $p<0.001)$. After division into 6 -h intervals, a significantly lower number of OHCA cases occurred between 00:00 and 05:59 (12.3\%) in comparison to the highest number observed in between 06:00 and 11:59 (12.3\% vs. 33.5\%, $p<0.001)$. The highest OHCA occurrence was observed on Monday (14.9\%), however, no weekly variability was found ( $p=0.557)$. The highest OHCA occurrence was observed in the winter and lowest in the summer $(27.4 \%$ vs. $22.8 \%, p<0.001)$. Significant circadian variability was observed for every day of the week, every season and year during the observation period $(p<0.001)$.

Conclusions: Circadian, monthly and seasonal variability of OHCA occurrence was confirmed in the long-term observation with no differences between particular days of the week. Significant circadian variability was observed within days of the week, seasons of the year, and particular years. (Cardiol J)
\end{abstract}

Key words: out-of-hospital cardiac arrest (OHCA), temporal variability, circadian, seasonal, weekly

Address for correspondence: Jakub Ratajczak, MD, Department of Cardiology and Internal Medicine/Department of Health Promotion, Nicolaus Copernicus University, Collegium Medicum in Bydgoszcz, ul. Marii Skłodowskiej-Curie 9, 85-094 Bydgoszcz, Poland, tel: +48 5258540 23; fax: +48 5258540 24, e-mail: ratajczak.j.m@gmail.com

Received: 9.03.2021 Accepted: 5.06.2021 Early publication date: 9.06.2021

*Stanistaw Szczerbinski and Jakub Ratajczak are equal contributors.

This article is available in open access under Creative Common Attribution-Non-Commercial-No Derivatives 4.0 International (CC BY-NC-ND 4.0) license, allowing to download articles and share them with others as long as they credit the authors and the publisher, but without permission to change them in any way or use them commercially. 


\section{Introduction}

Out-of-hospital cardiac arrest (OHCA) is still considered a major health problem globally and although much progress in the case of diagnosis and treatment has been made OHCA remains one of the major causes of death worldwide [1]. In Poland, the incidence of OHCA in different studies was estimated as $57-170$ per 100,000 inhabitants per year [2-4]. The occurrence of cardiac arrest is related to social, behavioral, clinical, and environmental risk factors, e.g., time variables $[2,5]$, weather conditions, and pollution [2, 6-8]. Temporal variability, especially the circadian rhythm of OHCA occurrence, is a well-documented phenomenon [8]. Previous studies also provided evidence for weekly $[5,10-15]$, monthly and seasonal variability $[4,5$, $10,12,15-17]$, however, the results are less uniform. Circadian changes in blood pressure, vascular tone, urinary catecholamines levels, endothelial function, and circulating levels of humoral signals related to activation of the sympathetic nervous system could be the potential cause of temporal variation of OHCA occurrence $[18,19]$. In a previous study, typical circadian variation of $\mathrm{OHCA}$ incidence in a subpopulation of southern Poland was confirmed [2]. Furthermore, the study showed weekly variability with the highest incidence of OHCA from Saturday to Monday, and the lowest in the middle of the week (Tuesday to Friday), and seasonal variability with the lowest OHCA occurrence during summer. Available data regarding the epidemiology of OHCA in Poland is still scarce and limited only to $12-24$ months of observation. The aim of this study was to investigate the temporal variability of OHCA occurrence over a long timeperiod and analyze the circadian pattern among days of the week and seasons of the year.

\section{Methods}

\section{Setting and data collection}

A retrospective analysis of dispatch cards from the Emergency Medical Service in Opole was performed covering the period from January $1^{\text {st }}, 2006$ to December $31^{\text {st }}, 2018$. Opole district is located in the south-western part of Poland, covers an area of $1683 \mathrm{~km}^{2}$, and was inhabited during the study period by approximately 261,000 citizens (47.7\% of men).

Patients older than 18 years of age with presumed cardiac etiology were included in the analysis regardless of the initial rhythm, the presence

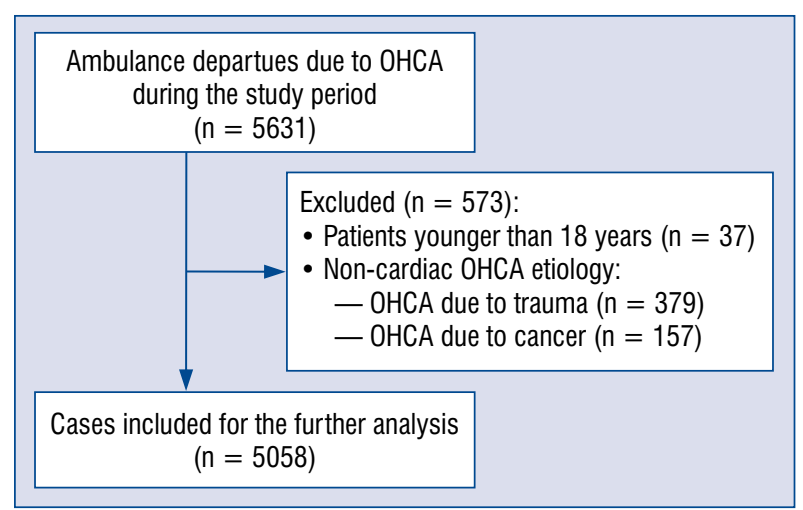

Figure 1. Numbers of cases initially screened, excluded and included for further analysis during the study period 2006-2018; OHCA — out-of-hospital cardiac arrest.

of witnesses, or whether cardiopulmonary resuscitation was performed. All cases with late signs of death (i.e., rigor mortis, postmortem lividity or presence of decomposition) were excluded from the analysis. Patients under 18 years of age and those with non-cardiac etiology were also excluded. Detailed information regarding a screening process and exclusions is presented in Figure 1. During the study period, a total of 5058 cases fulfilled the inclusion criteria and were statistically analyzed.

To stay consistent and maintain comparability with the previous reports, the following patterns of time periods were used to analyze the OHCA occurrence. Circadian rhythm was investigated within twenty-four 1-hour periods and four 6-hour intervals: "night" (0:00-5:59), "morning" (6:00-11:59), "afternoon" (12:00-17:59), and “evening" (18:00-23:59). Weekly variability was assessed between particular days, as well as, between weekdays (Monday to Friday) and weekend (Saturday and Sunday). OHCA occurrence between the Saturday-Monday period and the Tuesday-Friday period was also compared. The seasons were defined as spring (March, April, May), summer (June, July, August), autumn (September, October, November), and winter (December, January, February). The circadian variability of OHCA occurrence was investigated within particular years, seasons of the year and days of the week.

The present study was approved by the Ethics Committee of The Nicolaus Copernicus University in Torun, Collegium Medicum in Bydgoszcz (number of the approval KB 471/2013) and was conducted in accordance with Declaration of Helsinki and Good Clinical Practice guidelines. 


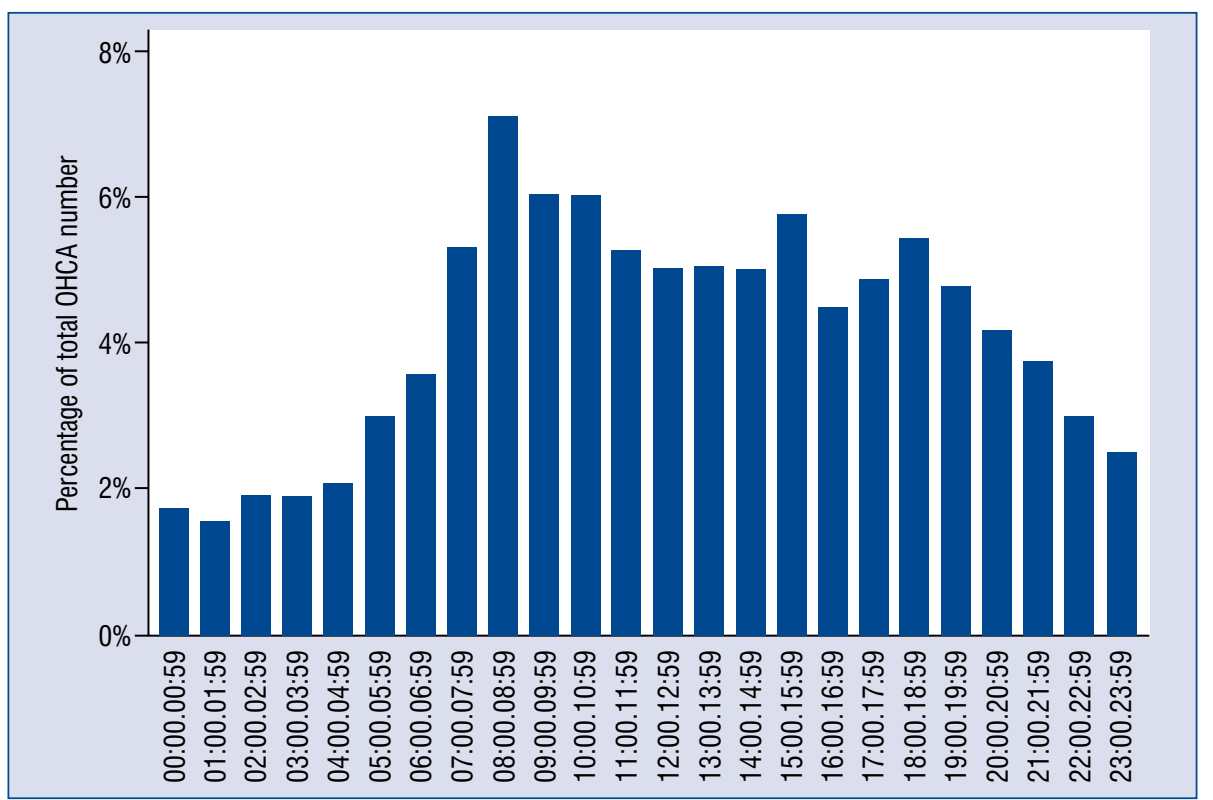

Figure 2. Circadian distribution of out-of-hospital cardiac arrest (OHCA) occurrence divided into 1-hour periods.

\section{Statistical analysis}

Statistical analysis was performed with the IBM SPSS Statistic version 23. The distribution of the data was analyzed using the Shapiro-Wilk test. Continuous variables were presented as means \pm standard deviation (SD) or medians with interquartile range (IQR) and categorical variables as absolute values and percentages. Although temporal variation of OHCA was generally distributed non-normally it was decided to present the data as percentages/means \pm SD to better visualize the differences. The differences between variables were tested using the Mann-Whitney test or the Kruskall-Willis test for non-normally distributed data and the Student t-test or ANOVA for data with a normal distribution. For statistical significance a two-sided p-value $<0.05$ was applied.

\section{Results}

\section{Temporal variability within the total population}

The mean age of patients included in the analysis was $69.41 \pm 14.86$ years with the majority of men $(64.1 \%)$. The circadian distribution of OHCA cases is presented in Figure 2. The highest incidence was observed between 08:00 and 08:59 and the lowest between 01:00 and 01:59 (7.1\% vs. $1.6 \%, 3.97 \pm 2.258$ vs. $0.88 \pm 0.964, \mathrm{p}<0.001)$. After division into 6 -hour intervals, the lowest number of OHCA cases occurred at "night" $(n=623$,
$12.3 \%)$ and was lower in comparison to the highest number observed in the "morning" ( $\mathrm{n}=1694$, $33.5 \%, \mathrm{p}<0.001)$. The OHCA incidence at "night" was also lower than in the "afternoon" and "evening" ( $\mathrm{p}<0.001)$.

The highest OHCA occurrence was observed on Monday ( $\mathrm{n}=752,14.9 \%)$ and the lowest on Wednesday $(\mathrm{n}=684,13.5 \%)$ however, no weekly variability was found $(\mathrm{p}=0.557)$. No difference was observed between the weekend and the weekdays $(1.06 \pm 1.126$ vs. $1.07 \pm 1.089, \mathrm{p}=0.65)$ and between the Saturday-Monday period and the rest of the week $(1.08 \pm 1.115$ vs. $1.06 \pm 1.089, \mathrm{p}=0.66)$.

Both monthly and seasonal variability was confirmed $(p<0.001)$. The highest proportion of OHCA cases was noted in December $(\mathrm{n}=480$, $9.5 \%)$ and January $(\mathrm{n}=484,9.6 \%)$ while the lowest was in July ( $\mathrm{n}=378,7.5 \%)$ and August $(\mathrm{n}=361$, $7.1 \%$ ). Similar results were observed for seasonal variability with the highest $\mathrm{OHCA}$ occurrence in the winter $(\mathrm{n}=1386,27.4 \%, 1.18 \pm 1.169)$ and lowest in the summer $(\mathrm{n}=1153,22.8 \%, 0.96 \pm 1.066)$.

\section{Circadian variability within \\ days of the week}

For each particular day of the week, circadian variability $(\mathrm{p}<0.001)$ was observed. The lowest number of OHCA cases was noted between 00:00 and 05:59 (Fig. 3) and the highest was reported between 06:00 and 11:59 on every weekday except Thursday when a slightly higher number 


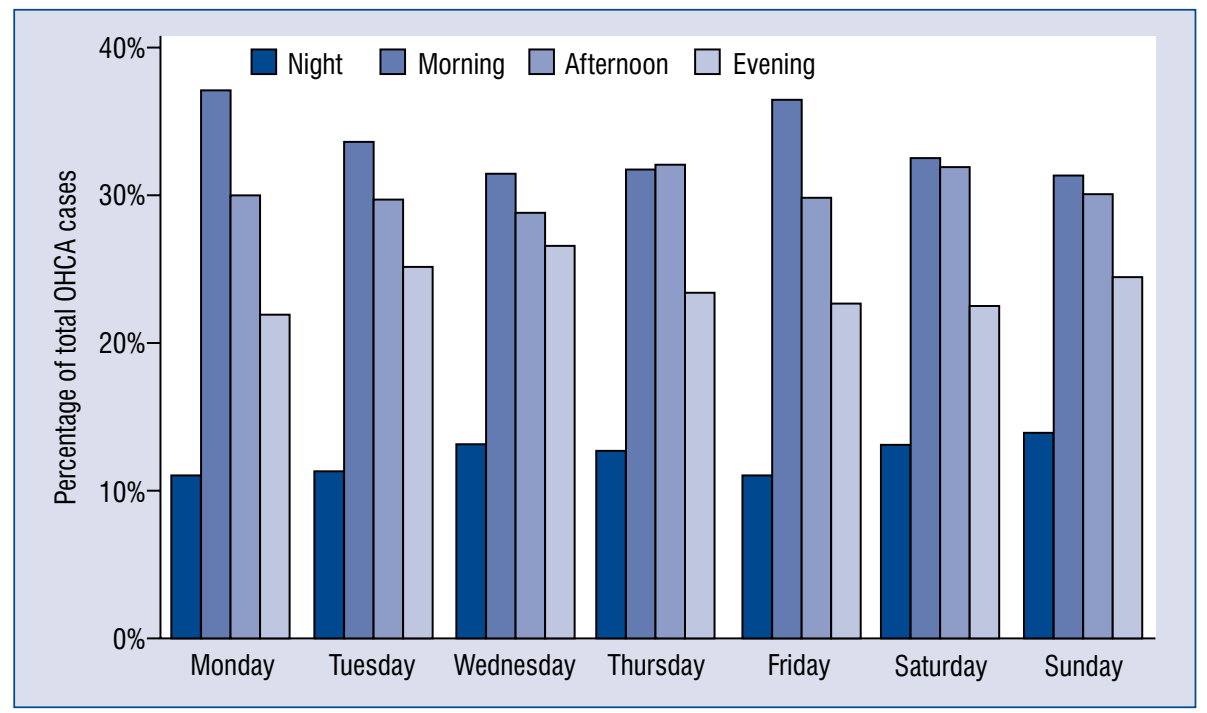

Figure 3. Circadian distribution of out-of-hospital cardiac arrest (OHCA) cases divided into 6-hour intervals within days of the week.

Table 1. Mean values of out-of-hospital cardiac arrest occurrence during particular times of the day divided into 6-hour intervals within days of the week.

\begin{tabular}{lcccccccc}
\hline \multirow{2}{*}{$\begin{array}{l}\text { Time of } \\
\text { the day }\end{array}$} & \multicolumn{7}{c}{ Days of the week (mean \pm standard deviation) } & P \\
\cline { 2 - 8 } & Monday & Tuesday & Wednesday & Thursday & Friday & Saturday & Sunday \\
\hline Night & $1.06 \pm 0.99$ & $1.05 \pm 0.98$ & $1.15 \pm 1.23$ & $1.18 \pm 0.99$ & $1.03 \pm 1.03$ & $1.22 \pm 1.22$ & $1.29 \pm 1.22$ & 0.828 \\
Morning & $3.58 \pm 1.96$ & $3.13 \pm 1.96$ & $2.76 \pm 1.67$ & $2.94 \pm 1.69$ & $3.40 \pm 2.18$ & $3.01 \pm 2.08$ & $2.91 \pm 1.76$ & 0.127 \\
Afternoon & $2.88 \pm 1.44$ & $2.77 \pm 1.91$ & $2.53 \pm 2.03$ & $2.97 \pm 1.66$ & $2.78 \pm 1.57$ & $2.96 \pm 1.73$ & $2.79 \pm 1.55$ & 0.542 \\
Evening & $2.12 \pm 1.61$ & $2.35 \pm 1.49$ & $2.33 \pm 1.73$ & $2.17 \pm 1.53$ & $2.12 \pm 1.49$ & $2.09 \pm 1.57$ & $2.28 \pm 1.71$ & 0.862 \\
\hline
\end{tabular}

was observed between 12:00 and 17:59. The analysis of the circadian variation within weekend and weekdays also showed significant results $(\mathrm{p}<0.001)$ with the same pattern for both groups: the lowest OHCA occurrence was observed at "night" $(\mathrm{n}=196,13.5 \%, 1.26 \pm 1.217$ and $\mathrm{n}=427,11.8 \%, 1.09 \pm 1.043$, respectively) and the highest in the "morning" period $(\mathrm{n}=462,31.9 \%$, $2.96 \pm 1.921$ and $n=1232,34.1 \%, 3.16 \pm 1.915$, respectively). Similar results regarding circadian variation were found for the Saturday-Monday period and the Thursday-Friday period $(\mathrm{p}<0.001$ for both). No differences were found regarding the particular times of the day ("night", "morning", "afternoon", and "evening") among the days of the week (Table 1).

\section{Circadian variability within} seasons of the year

The circadian variability was confirmed for every season of the year ( $\mathrm{p}<0.001$; Fig. 4$)$. This figure shows the circadian distribution of OHCA cases divided into 6-hour intervals within particular seasons. The highest OHCA incidence was observed between 6:00 and 11:59 in spring $(\mathrm{n}=459$, $35.5 \%, 1.96 \pm 1.47)$, autumn $(\mathrm{n}=416,33.8 \%$, $1.78 \pm 1.25)$, and winter $(\mathrm{n}=492,35.5 \%, 2.1 \pm$ \pm 1.58 ). During the summer period, the highest number of cases occurred between 12:00 and 17:59 ( $\mathrm{n}=381,33.0 \%, 1.62 \pm 1.35)$. However, post-hoc analysis revealed no significance between the "morning" and the "afternoon" in any season. The lowest number of OHCA cases occurred at "night" $(\mathrm{p}<0.001)$ and the same observation was true for every season. A significantly lower occurrence was noticed in the "evening" compared to the "morning" and the "afternoon" in spring, autumn, and winter.

Inter-season analysis showed no differences regarding "night", "afternoon" and "evening" periods (Table 2). Significant variability was observed regarding the "morning" period. Summer was the 


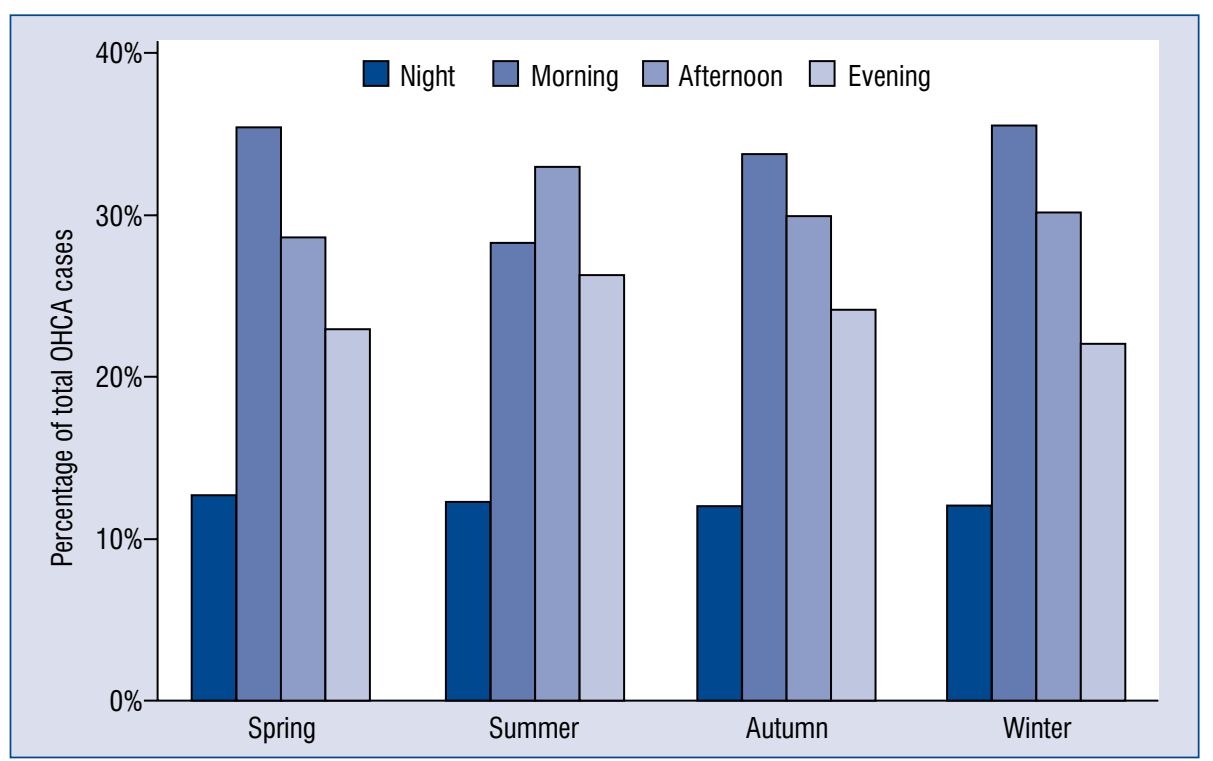

Figure 4. Circadian distribution of out-of-hospital cardiac arrest (OHCA) cases divided into 6-hour intervals within seasons of the year.

Table 2. Mean values of out-of-hospital cardiac arrest occurrence during particular times of the day divided into 6-hour intervals within seasons of the year.

\begin{tabular}{lccccc}
\hline \multirow{2}{*}{ Time of the day } & \multicolumn{4}{c}{ Seasons of the year (mean \pm standard deviation) } & P \\
\cline { 2 - 5 } & Spring & Summer & Autumn & Winter & \\
\hline Night & $0.71 \pm 0.93$ & $0.61 \pm 0.84$ & $0.63 \pm 0.82$ & $0.72 \pm 0.91$ & 0.482 \\
Morning & $1.96 \pm 1.47$ & $1.40 \pm 1.26$ & $1.78 \pm 1.25$ & $2.10 \pm 1.58$ & $<0.001$ \\
Afternoon & $1.59 \pm 1.20$ & $1.63 \pm 1.35$ & $1.57 \pm 1.29$ & $1.79 \pm 1.43$ & 0.478 \\
Evening & $1.27 \pm 1.19$ & $1.29 \pm 1.20$ & $1.27 \pm 1.26$ & $1.31 \pm 1.20$ & 0.951 \\
\hline
\end{tabular}

season with the lowest OHCA cases in the morning $(\mathrm{n}=327,28.4 \%, 1.63 \pm 1.35, \mathrm{p}<0.001)$.

\section{Circadian variability within years}

The circadian distribution of OHCA cases within each year is presented in Figure 5. Statistically significant differences within 6 -hour intervals were observed for every year during the study period ( $\mathrm{p}<0.001)$. Each year the lowest number of OHCA cases (range: $\mathrm{n}=37-57,10.2-15.1 \%$, range of the mean: $0.51 \pm 0.82$ to $0.79 \pm 0.9$ ) occurred during the "night" period and differed significantly from the incidence in the "morning" $(\mathrm{p}<0.001)$ and the "afternoon" $(\mathrm{p}<0.01)$. At night the number of OHCA cases was lower in comparison to the "evening" period but did not reach statistical significance in $2008(\mathrm{p}=0.122)$, $2013(\mathrm{p}=0.181)$, and $2015(\mathrm{p}=0.159)$. No differences were observed between the "morning" and the "afternoon" time periods ( $\mathrm{p}>0.447)$. Lower OHCA occurrence in the "evening" in comparison to the "afternoon" was noticed in $2011(\mathrm{p}=0.01)$ and $2015(\mathrm{p}=0.001)$. The significant difference between the "morning" and the "evening" time period was noticed in $2009(\mathrm{p}=0.017), 2011$ ( $<<0.001), 2012(\mathrm{p}=0.001), 2013(\mathrm{p}=0.043)$, and $2015(\mathrm{p}=0.003)$. No differences in OHCA occurrence at "night" were observed in the year-to-year analysis. Similar results, but less marked, were noticed also for "morning", "afternoon", and “evening” periods (Table 3 ).

\section{Discussion}

In the current study, temporal variation patterns of OHCA occurrence in southern Poland within the 13-year period were examined. Presented results confirm the circadian variability 


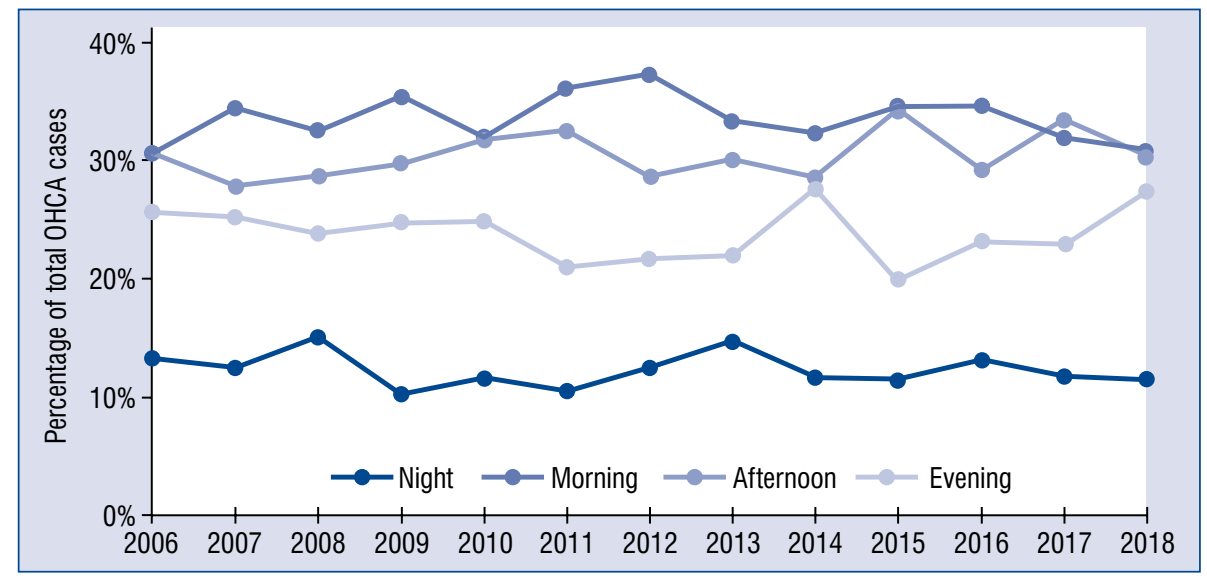

Figure 5. Circadian distribution of out-of-hospital cardiac arrest (OHCA) cases divided into 6-hour intervals within the years.

Table 3. Mean and total values of out-of-hospital cardiac arrest (OHCA) occurrence during particular time of the day divided into 6-hour intervals within seasons of the year.

\begin{tabular}{lcccc}
\hline Year & \multicolumn{3}{c}{ Total number of OHCA (mean \pm standard deviation) } \\
\cline { 2 - 5 } & Night & Morning & Afternoon & Evening \\
\hline 2006 & $53(0.79 \pm 0.95)$ & $123(1.71 \pm 1.39)$ & $123(1.71 \pm 1.33)$ & $103(1.43 \pm 1.02)$ \\
2007 & $51(0.71 \pm 0.93)$ & $141(1.96 \pm 1.63)$ & $114(1.58 \pm 1.18)$ & $103(1.43 \pm 1.27)$ \\
2008 & $57(0.79 \pm 0.90)$ & $123(1.71 \pm 1.45)$ & $108(1.5 \pm 1.23)$ & $90(1.25 \pm 1.17)$ \\
2009 & $39(0.54 \pm 0.77)$ & $135(1.88 \pm 1.26)$ & $113(1.57 \pm 1.42)$ & $94(1.31 \pm 1.32)$ \\
2010 & $47(0.65 \pm 0.81)$ & $130(1.81 \pm 1.57)$ & $129(1.79 \pm 1.34)$ & $101(1.4 \pm 1.27)$ \\
2011 & $41(0.57 \pm 0.77)$ & $141(1.96 \pm 1.34)$ & $127(1.76 \pm 1.28)$ & $82(1.14 \pm 1.19)$ \\
2012 & $56(0.78 \pm 1.01)$ & $167(2.32 \pm 1.61)$ & $128(1.78 \pm 1.32)$ & $97(1.35 \pm 1.21)$ \\
2013 & $53(0.74 \pm 0.98)$ & $120(1.67 \pm 1.38)$ & $108(1.5 \pm 1.02)$ & $79(1.1 \pm 1.06)$ \\
2014 & $37(0.51 \pm 0.82)$ & $103(1.43 \pm 1.28)$ & $91(1.26 \pm 1.29)$ & $88(1.22 \pm 1.25)$ \\
2015 & $41(0.57 \pm 0.75)$ & $124(1.72 \pm 1.32)$ & $123(1.71 \pm 1.22)$ & $71(0.99 \pm 1.11)$ \\
2016 & $43(0.6 \pm 0.83)$ & $114(1.58 \pm 1.32)$ & $96(1.33 \pm 1.16)$ & $76(1.06 \pm 0.93)$ \\
2017 & $48(0.67 \pm 0.93)$ & $131(1.82 \pm 1.21)$ & $137(1.9 \pm 1.60)$ & $94(1.31 \pm 1.15)$ \\
2018 & $53(0.74 \pm 0.87)$ & $142(1.97 \pm 1.52)$ & $140(1.94 \pm 1.57)$ & $126(1.75 \pm 1.59)$ \\
$P$ & 0.549 & 0.066 & 0.080 & 0.065 \\
\hline
\end{tabular}

of OHCA with morning peak and nighttime nadir. Furthermore, similar results of temporal variability within 24-hours were observed within days of the week, months, seasons, and years. In all cases, night was the period with the lowest OHCA occurrence and morning with the highest in most of the cases with some exceptions when slightly higher values were observed in the afternoon. Contrary to previous results, no significant weekly variability was observed, however monthly and seasonal differences in the occurrence of OHCA were confirmed [2].
The circadian variability of OHCA occurrence was observed in many previous studies. Presented results show, in line with other reports, the lowest number of OHCA cases during the night hours with a consequent morning peak [10, 11, 13, 20, 21]. The majority of previous studies also reported secondary, smaller peaks in the OHCA occurrence present in the late afternoon (16:00-20:00) with some exceptions. Baert et al. [21] did not report a secondary afternoon peak and on the other hand, Soo et al. [22] reported a trimodal pattern of the OHCA distribution. Three peaks were also 
observed in our previously published paper [2] however, the present report contains a significantly larger number of cases and the afternoon peak seemed to blur. The typical increase of cases in the morning could potentially be explained by an increase in platelet aggregability, changes in blood pressure, endothelial function, and catecholamine levels which could potentially result in the occurrence of acute coronary syndrome.

The highest number of OHCA cases was observed on Monday and the lowest on Wednesday however, the weekly variability was not significant in the present study. Very similar results were reported by Nakanishi et al. [17] but on a smaller number of OHCA patients with presumed cardiac etiology for whom resuscitation by emergency medical service was attempted. Previous reports showed some evidence for Monday excess especially within a subgroup of younger patients [10, 14-16]. It was explained by increased stress due to returning to work as a potential trigger for OHCA occurrence in this group. However, available data is inconclusive. Nakanishi et al. [17] showed an opposite relationship with significantly higher OHCA cases on Monday in patients older than 65 years and no significant difference in the younger group. Other studies revealed the highest number of patients with cardiac arrest on Saturday [5, 13], which could be explained by some strenuous physical activities undertaken during patient's free time on weekends. In our previous study, we presented a significantly higher OHCA number within the Saturday-Monday period in comparison to the rest of the week. Actual results showed a small difference between those two periods but with no statistical significance.

The present study results suggest a strong association between OHCA occurrence and the season of the year, with the highest proportion of cases during the winter and the lowest during the summer. This observation is in line with many previously published studies conducted in a temperate climate [5, 10, 12, 15-17]. On the other hand, Ong et al. [23] investigated cardiac arrest occurrence in the equatorial climate of Singapore and did not confirm the seasonal variability. Therefore, the seasonal variability might be explained by some weather conditions related to the climate, e.g., ambient temperature, humidity, and atmospheric pressure [6, 7]. The Australian study [24] also confirmed a similar pattern of higher OHCA incidence in the winter, which in the southern hemisphere occurs in June, July, and August. Various studies investigated the relationship between OHCA oc- currence and ambient temperature and revealed the link between the increased number of cases and extreme temperatures. The cold was especially strongly related to the higher OHCA occurrence $[7,25,26]$. Besides the weather-related factor, the seasonal variability might also be potentially explained by the air pollution [8] or in some areas by tourism [27]. Winter overlaps also with the period of increased morbidity due to infectious diseases. A study by Onozuka and Hagihara [28] showed an association between influenza epidemics and a higher risk of OHCA. Furthermore, preliminary data from the novel severe acute respiratory syndrome coronavirus 2 (SARS-CoV-2) pandemic also presented a potential relationship with increased OHCA occurrence [29]. Borkowska et al. [30] presented results regarding OHCA during the coronavirus disease 2019 (COVID-19) pandemic and reported that during March and April 2020 the OHCA incidence within Masovia Voivodeship was 12.2 per 100,000 inhabitants, which is lower in comparison to previous Polish studies [2-4]. However, it should be noticed that in March and April 2020 in Poland the epidemic was just starting to develop, the number of confirmed SARS-CoV-2 infections was very low and the first government restrictions were being implemented. On the contrary, a metanalysis by Lim et al. [31] revealed almost $120 \%$ increase in OHCA events during the 2020 COVID-19 pandemic in comparison to the pre-pandemic time. Furthermore, recent evidence showed that COVID-19 infection was related to reduced rates of achieving the return of spontaneous circulation, shockable rhythms, and survival to hospital discharge in patients with OHCA [32]. However, data regarding in-hospital cardiac arrest were more inconclusive [33].

According to available research, only a few previous studies reported the circadian variation of OHCA cases within particular days of the week [34], and none described circadian distribution within months, seasons, and years. Arntz et al. [10] reported a similar circadian distribution of sudden cardiac death for every day of the week and with similar observations to our study. In the present study, the pattern with the lowest number of OHCA cases was during night hours with an increase in the latter part of the day and was observed on all weekdays except Thursday when the highest number was observed in the afternoon. However, within all days of the week the difference between morning and afternoon occurrence was not significant. In the previous study, the circadian pattern of OHCA distribution differed between border- 
week days (Saturday to Monday) in comparison to mid-week days (Tuesday to Friday) with no clear morning peak in the latter [34]. On the contrary, the present study noted a similar pattern both for the Saturday-Monday and the Tuesday-Friday periods as well as for weekdays and weekends. Observed differences between those two reports may result from the sample size in both studies.

The presented study has several limitations that should be underlined. Firstly, the retrospective nature of the study and the lack of some data, mainly regarding patients' socio-economic status, as well as their medical history. However, the aim of this observational study was to investigate the chronobiology of OHCA occurrence, therefore further studies should be conducted in order to investigate the influence of various factors on $\mathrm{OHCA}$ occurrence in particular timeframes. Secondly, the analysis on data concerning survival, witnessed status, or initial cardiac rhythm was not performed. The observation covered a long time period but was limited to the relatively small territory of the Opole district in southern Poland.

\section{Conclusions}

Circadian, monthly and seasonal variability of OHCA occurrence was confirmed in the long-term observation with no differences between particular weekdays. The lowest number of OHCA cases occurred at night and in the summer. Significant circadian variability of OHCA occurrence was observed within the days of the week, seasons of the year, and of particular years during the 13 year observation period.

\section{Conflict of interest: None declared}

\section{References}

1. Hollenberg J, Svensson L, Rosenqvist M. Out-of-hospital cardiac arrest: 10 years of progress in research and treatment. J Intern Med. 2013; 273(6): 572-583, doi: 10.1111/joim.12064, indexed in Pubmed: 23480824.

2. Szczerbinski S, Ratajczak J, Lach P, et al. Epidemiology and chronobiology of out-of-hospital cardiac arrest in a subpopulation of southern Poland: A two-year observation. Cardiol J. 2020; 27(1): 16-24, doi: 10.5603/CJ.a2018.0025, indexed in Pubmed: 29611174.

3. Nadolny K, Zyśko D, Obremska M, et al. Analysis of out-ofhospital cardiac arrest in Poland in a 1-year period: data from the POL-OHCA registry. Kardiol Pol. 2020; 78(5): 404-411, doi: 10.33963/KP.15241, indexed in Pubmed: 32191020.

4. Gach D, Nowak JU, Krzych $Ł J$. Epidemiology of out-of-hospital cardiac arrest in the Bielsko-Biala district: a 12-month analysis. Kardiol Pol. 2016; 74(10): 1180-1187, doi: 10.5603/ KP.a2016.0086, indexed in Pubmed: 27221961.

5. Jallow T, Wennberg P, Forslund AS. Temporal variation in out-of-hospital cardiac arrest with validated cardiac cause. Scand Cardiovasc J. 2018; 52(3): 149-155, doi: 10.1080/140174 31.2018.1453080, indexed in Pubmed: 29564930.

6. Ratajczak J, Łach P, Szczerbiński S, et al. Atmospheric conditions and the occurrence of out-of-hospital cardiac arrest in Poland preliminary analysis of poorly understood phenomena. Med Res J. 2018; 3(3): 121-126, doi: 10.5603/mrj.a2018.0019.

7. Hensel M, Geppert D, Kersten JF, et al. Association between weather-related factors and cardiac arrest of presumed cardiac etiology: a prospective observational study based on out-of-hospital care data. Prehosp Emerg Care. 2018; 22(3): 345-352, doi: 10.1080/10903127.2017.1381790, indexed in Pubmed: 29345516.

8. Kim JH, Hong J, Jung J, et al. Effect of meteorological factors and air pollutants on out-of-hospital cardiac arrests: a time series analysis. Heart. 2020; 106(16): 1218-1227, doi: 10.1136/ heartjnl-2019-316452, indexed in Pubmed: 32341139.

9. Kubica A, Szczerbiński S, Kieszkowska M, et al. Wpływ czynników klimatycznych i chronologicznych na występowanie ostrych incydentów chorobowych. Folia Cardiol. 2014; 9(3): 263-266.

10. Arntz HR, Willich SN, Schreiber C, et al. Diurnal, weekly and seasonal variation of sudden death. Population-based analysis of 24,061 consecutive cases. Eur Heart J. 2000; 21(4): 315-320, doi: 10.1053/euhj.1999.1739, indexed in Pubmed: 10653679.

11. Ni YM, Rusinaru C, Reinier K, et al. Unexpected shift in circadian and septadian variation of sudden cardiac arrest: the Oregon Sudden Unexpected Death Study. Heart Rhythm. 2019; 16(3): 411-415, doi: 10.1016/j.hrthm.2018.08.034, indexed in Pubmed: 30193852.

12. Allegra JR, Cochrane DG, Allegra EM, et al. Calendar patterns in the occurrence of cardiac arrest. Am J Emerg Med. 2002; 20(6): 513-517, doi: 10.1053/ajem.2002.34799, indexed in Pubmed: 12369023.

13. Brooks SC, Schmicker RH, Rea TD, et al. ROC Investigators. Out-of-hospital cardiac arrest frequency and survival: evidence for temporal variability. Resuscitation. 2010; 81(2): 175-181, doi: 10.1016/j.resuscitation.2009.10.021, indexed in Pubmed: 19942338.

14. Gruska M, Gaul GB, Winkler M, et al. Increased occurrence of out-of-hospital cardiac arrest on Mondays in a community-based study. Chronobiol Int. 2005; 22(1): 107-120, doi: 10.1081/cbi200041046, indexed in Pubmed: 15865325.

15. Herlitz J, Eek M, Holmberg M, et al. Diurnal, weekly and seasonal rhythm of out of hospital cardiac arrest in Sweden. Resuscitation. 2002; 54(2): 133-138, doi: 10.1016/s0300-9572(02)00097-7, indexed in Pubmed: 12161292.

16. Peckova M, Fahrenbruch CE, Cobb LA, et al. Weekly and seasonal variation in the incidence of cardiac arrests. Am Heart J. 1999; 137(3): 512-515, doi: 10.1016/s0002-8703(99)70507-7, indexed in Pubmed: 10047634.

17. Nakanishi N, Nishizawa S, Kitamura Y, et al. Circadian, weekly, and seasonal mortality variations in out-of-hospital cardiac arrest in Japan: analysis from AMI-Kyoto Multicenter Risk Study database. Am J Emerg Med. 2011; 29(9): 1037-1043, doi: 10.1016/j. ajem.2010.06.018, indexed in Pubmed: 20708890.

18. Rudic RD. Time is of the essence: vascular implications of the circadian clock. Circulation. 2009; 120(17): 1714-1721, doi: 
10.1161/CIRCULATIONAHA.109.853002, indexed in Pubmed: 19858424.

19. Nicolau GY, Haus E, Popescu M, et al. Circadian, weekly, and seasonal variations in cardiac mortality, blood pressure, and catecholamine excretion. Chronobiol Int. 1991; 8(2): 149-159, doi: 10.3109/07420529109059165, indexed in Pubmed: 1797411.

20. Peckova M, Fahrenbruch CE, Cobb LA, et al. Circadian variations in the occurrence of cardiac arrests: initial and repeat episodes. Circulation. 1998; 98(1): 31-39, doi: 10.1161/01.cir.98.1.31, indexed in Pubmed: 9665057.

21. Baert V, Vilhelm C, Escutnaire J, et al. on behalf GR-RéAC. Identification of a morning out-of-hospital cardiac arrest cluster of high-incidence: towards a chrono-preventive care strategy. J Eval Clin Pract. 2021; 27(1): 84-92, doi: 10.1111/jep.13390, indexed in Pubmed: 32212234.

22. Soo LH, Gray D, Young T, et al. Circadian variation in witnessed out of hospital cardiac arrest. Heart. 2000; 84(4): 370-376, doi: 10.1136/heart.84.4.370, indexed in Pubmed: 10995402.

23. Ong MEh, Ng FS, Yap S, et al. Temporal variation of out-ofhospital cardiac arrests in an equatorial climate. Open Access Emerg Med. 2010; 2: 37-43, doi: 10.2147/oaem.s9266, indexed in Pubmed: 27147836.

24. Muller A, Dyson K, Bernard S, et al. Seasonal variation in out-of-hospital cardiac arrest in Victoria 2008-2017: winter peak. Prehosp Emerg Care. 2020; 24(6): 769-777, doi: 10.1080/10903127.2019.1708518, indexed in Pubmed: 31906816.

25. Kang SH, Oh IY, Heo J, et al. Heat, heat waves, and out-ofhospital cardiac arrest. Int J Cardiol. 2016; 221: 232-237, doi: 10.1016/j.ijcard.2016.07.071, indexed in Pubmed: 27404681.

26. Onozuka D, Hagihara A. Extreme temperature and out-of-hospital cardiac arrest in Japan: a nationwide, retrospective, observational study. Sci Total Environ. 2017; 575: 258-264, doi: 10.1016/j.scitotenv.2016.10.045, indexed in Pubmed: 27744154.
27. Tammaro G, Picconi E, Scardia M, et al. Influence of summer tourist flows on occurrence of out-of-hospital cardiac arrest in an Italian tourist-intensive area. Int Emerg Nurs. 2020; 52: 100893, doi: 10.1016/j.ienj.2020.100893, indexed in Pubmed: 32791472.

28. Onozuka D, Hagihara A. Extreme influenza epidemics and out-of-hospital cardiac arrest. Int J Cardiol. 2018; 263: 158-162, doi: 10.1016/j.ijcard.2018.02.028, indexed in Pubmed: 29754914.

29. Marijon E, Karam N, Jost D, et al. Out-of-hospital cardiac arrest during the COVID-19 pandemic in Paris, France: a population-based, observational study. Lancet Public Health. 2020; 5(8): e437-e443, doi: 10.1016/S2468-2667(20)30117-1, indexed in Pubmed: 32473113.

30. Borkowska MJ, Smereka J, Safiejko K, et al. Out-of-hospital cardiac arrest treated by emergency medical service teams during COVID-19 pandemic: A retrospective cohort study. Cardiol J. 2021; 28(1): 15-22, doi: 10.5603/CJ.a2020.0135, indexed in Pubmed: 33140396.

31. Lim ZJ, Ponnapa Reddy M, Afroz A, et al. Incidence and outcome of out-of-hospital cardiac arrests in the COVID-19 era: A systematic review and meta-analysis. Resuscitation. 2020; 157: 248-258, doi: 10.1016/j.resuscitation.2020.10.025, indexed in Pubmed: 33137418.

32. Borkowska MJ, Jaguszewski MJ, Koda M, et al. Impact of coronavirus disease 2019 on out-of-hospital cardiac arrest survival rate: a systematic review with meta-analysis. J Clin Med. 2021; 10(6), doi: 10.3390/jcm10061209, indexed in Pubmed: 33803944.

33. Szarpak L, Borkowska M, Peacock FW, et al. Characteristics and outcomes of in-hospital cardiac arrest in COVID-19. A systematic review and meta-analysis. Cardiol J. 2021 [Epub ahead of print], doi: 10.5603/CJ.a2021.0043, indexed in Pubmed: 33942278.

34. Szczerbiński S. Observational, retrospective analysis of the circadian variability of out-of-hospital cardiac arrest within days of the week. Med Res J. 2020; 5(2): 68-71, doi: 10.5603/mrj.a2020.0020. 